\title{
PENGARUH KEPEMIMPINAN TRANSFORMASIONAL TERHADAP KEINOVATIFAN GURU SMA NEGERI KOTA LUBUKLINGGAU
}

\author{
Doni Pestalozi ${ }^{1}$, Rudi Erwandi ${ }^{2}$, M Rusni Eka Putra ${ }^{3}$ \\ STKIP PGRI Lubuklinggau ${ }^{1,2,3}$ \\ pestalozid@yahoo.co.id ${ }^{1}$
}

\begin{abstract}
ABSTRAK
Tujuan dari penelitian ini adalah unutuk mencari tahu apakah ada Pengaruh langsung positif kepemimpinan transformasional terhadap keinovatifan guru SMA Negeri di kota Lubuklinggau. Penelitian ini dirancang menggunakan metode survey dan dalam pengambilan data menggunakan kuesioner. Sampel pada penelitian ini adalah 38 guru dari SMA Negeri di kota Lubuklinggau. Hasil dari penelitian ini menunjukan bahwa terdapat pengaruh langsung positif kepemimpinan transformasional terhadap keinovatifan. Simpulan dari penelitian ini adalah didapatkan bahwa kepemimpinan transformasional kepala sekolah efektif, keinovatifan guru tinggi.
\end{abstract}

Keyword: Pengaruh, Kepemimpinan Transpforsional, Inovasi, Guru

\begin{abstract}
The purpose of this study is to find out whether there is a direct positive relationship between teachers of public high schools in the city of Lubuklinggau. This study was designed using a survey method and in data collection using a questionnaire. The sample in this study were 38 teachers from Public High Schools in the city of Lubuklinggau. The results of this study indicate that there is a positive direct effect of transformational leadership on innovation. The conclusions from this study are the results of the transformation of effective principals, the innovation of high teachers.
\end{abstract}

Keywords: Influence, Transparency of Leadership, Innovation, Teacher.

\section{PENDAHULUAN}

Berbagai kajian mengenai kepemimpinan transformasional memunculkan konsep-konsep yang relatif beragam mengenai kepemimpinan transformasional. Secara sederhana Tichy dan Ulrich (2013) menyatakan, "Transformational leadership is about renovating an organization; it is about transmuting the firm following a new vision which will lead to the evolution of the organization's culture. Konsep ini menekankan bahwa kepemimpinan transformasional merupakan kepemimpinan tentang merenovasi sebuah organisasi melalui visi baru yang menyebabkan terjadinya evolusi budaya organisasi. Dalam batasan ini kepemimpinan transformasional merupakan kemampuan seorang pemimpin untuk membuat orang mau berubah, meningkatkan diri, dan mau dipimpin.Berdasarkan 
konsep-konsep ini kepemimpinan transformasional pada dasarnya merupakan kepemimpinan tentang perubahan. Teori tentang kepemimpinan transformasional pertama kali dikembangkan oleh Burns pada tahun 1978 dalam analisisnya mengenai pemimpin politik. Dikemukakan oleh Burn sebagaimana dikutip oleh Roger J. Givens kepemimpinan transformasional adalah.Leadership as that which "occurs when one or more persons engage with others in such a way that leaders and followers raise one another to higher levels of motivation and morality"(Bass, 1985).Selanjutnya Burn sebagaimana dikutip oleh Araujo menjelaskan bahwa," Through strong vision and personality, transformational leaders are able to inspire followers to change expectations, perceptions and motivations to work towards common goals.Berdasarkan batasan ini dapat dikatakan bahwa pemimpin transformasional adalah pemimpin yang memotivasi para pengikutnya untuk bekerja atas dasar tujuan bersama dan dalam rangka memenuhi harapan-harapan perubahan melalui visi dan kepribadiannya yang kuat.

Senada dengan pendapat di atas Bass mengatakan bahwa pemimpin adalah "one who motivates us to do more than we originally expected to do". Pemimpin adalah seseorang yang memotivasi kita untuk bekerja melampaui apa yang diharapkan sebelumnya. Menurut Bass motivasi ini dapat dicapai dengan meningkatkan kesadaran mengenai pentingnya hasil (outcome) serta cara-cara untuk mencapainya. Selanjutnya Bass juga mengatakan bahwa pemimpin mendorong para pengikutnya untuk mengesampingkan kepentingan pribadi demi kepentingan tim atau organisasi.

Berdasarkan definisi-definisi di atas dapat disimpulkan bahwa dalam kepemimpinan transformasional terdapat karakteristik-karakteristik sebagai berikut: 1) adanya hubungan saling mempengaruhi antara pemimpin dan para pengikutnya dalam rangka meningkatkan motivasi dan moralitas, 2) adanya dorongan pemimpin agar para pengikutnya berpencapaian melebihi apa yang telah diharapkan sebelumnya, 3) adanya dorongan agar para pengikutnya lebih mengutamakan kepentingan tim daripada kepentingan pribadi, 4) pemimpin menginspirasi para pengikutnya melalui visi dan kepribadiannya yang kuat.

Dalam perkembangannya berbagai ahli memberikan pandangannya mengenai konsep kepemimpinan transformasional. Menurut Colquitt, LePine, dan Wesson, (2011) "transformational leadership is leadership that involves inspiring followers to commit to a shared vision that provides meaning to their work while also serving as a role model who help followers develop their own potential and view problems from new perspective". Relevan dengan pendapat ini McShane dan Von Glinow (2010) menegaskan "transformational leadership is a leadership perspective that explains how leaders change teams or organizations by creating, communicating, and modeling a vision forthe organization or work unit and inspiring employees to strive for that vision". Berdasarkan definisi-definisi ini dapat disimpulkan bahwa pemimpin transformasional merupakan pemimpin yang berjiwa insprirator yang menginspirasi para pengikutnya untuk berkomitmen 
terhadap tujuan-tujuan organisasi dan menjadi contoh atau model dalam mengembangkan potensi para pengikutnya.

Senada dengan pendapat di atas Stephen P. Robbins dan Timothy A. Judge (2013) menyatakan "transformational leaders are leaders who inspire follower to transcend their self-interests and who are capable of having a profound and extra ordinary effect on followers. Pemimpin transformasional menginspirasi para pengikutnya untuk lebih mengutamakan kepentingan bersama daripada kepentingan individu.Pemimpin transformasional memiliki kemampuan yang kuat untuk mempengaruhi para pengikutnya.

Menurut James L. Gibson (2012) "Transformational leadership is the ability to inspire and motivate followers to achieve results greater than originally planned for internal rewards". Kepemimpinan transformasional merupakan kemampuan untuk menginspirasi dan memotivasi para pengikut untuk berpencapaian melampaui apa yang telah diharapkan sebelumnya. Definisi ini menegaskan bahwa pemimpin transformasional merupakan sosok inspirator dan motivator.

Menurut Kinicki dan Kreitner (2010) "transformational leaders engender trust, seek to develop leadership in others, exhibit self-sacrifice and serve as moral agents, focusing themselves and followers on objectives that transcend the more immediate needs of the group". Hal senada dikemukakan oleh Jennifer M. George \& Gareth R. Jones(2012) "Transformational leader is leadership that inspires followers to trust the leader, perform behaviors that contribute to the achievement of organizational goals, and perform at high levels". Berdasarkan definisi ini dapat dikatakan bahwa pemimpin transformasional menumbuhkan kepercayaan dan kesediaan para pengikutnya untuk berkorban demi kepentingan organisasi, serta menunjukkan perilaku yang mendukung produktivitas organisasi secara optimal. Sebagai agen moral pemimpin transformasional membimbing para pengikutnya menjadi sosok yang memiliki integritas.

Dalam konteks organisasi sekolah, Hallinger (2013) mengemukakan, "transformational leadership focuses on developing the organization capacity to innovate". Pernyataan ini menegaskan bahwa kepemimpinan transformasional merupakan kepemimpinan inovasi. Selanjutnya menurut Hallinger “Transformational leadership seeks to build the organization's capacity to select its purposes and to support the development of changes to practices of teaching and learning". Kepemimpinan transformasional berupaya membangun kemampuan organisasi untuk menentukan tujuannya dan untuk mendukung perkembangan perubahan terhadap praktek-praktek pembelajaran.

Dengan melihat perbedaan-perbedaan antara kepemimpinan transformasional dan kepemimpinan transaksional, Colquitt, LePine, dan Wesson menegaskan bahwa spektrum kepemimpinan transformasional dapat dikelompokkan kedalam empat dimensi yaitu idealized influence, inspirational motivation, intellectual stimulation, dan individualized consideration. Idealized 
influence merupakan perilaku-perilaku pemimpin yang mendatangkan kekaguman, kepercayaan, dan rasa hormat para pengikutnya. Inspirational motivation meliputi perilaku-perilaku pemimpin yang menumbuh kembangkan antusiame dan komitmen para pengikutnya terhadap visi bersama.Intellectual stimulation meliputi perilaku-perilaku pemimpin yang memberikan tantangan terhadap para pengikutnya untuk menjadi inovatif dan kreatif dengan mempertanyakan asumsi-asumsi dan memikirkan kembali situasi-situasi lama melalui cara-cara baru. Individualized consideration meliputi perilaku-perilaku pemimpin yang membantu para pengikutnya mencapai potensinya melalui latihan, pengembangan, dan mentor.

Menurut Robbins dan Judge, pemimpin transformasional lebih efektif karena pemimpin transformasional merupakan sosok yang lebih kreatif dan senantiasa mendorong para pengikutnya untuk juga menjadi kreatif. Hal senada dikemukakan oleh Hellriegel \& Slocum yang menyatakan bahwa pemimpin transformasional mendorong para pengikutnya untuk menjadi inovatif dan kreatif dengan mempertanyakan asumsi-asumsi, menggali ide-ide dan metode baru, dan mengadakan pendekatan terhadap situasi-situasi lama dengan cara-cara baru. Secara rinci Yulk sebagaimana dikutip oleh Mullins menggambarkan sosok pemimpin transformasional sebagai berikut: (1) mengartikulasikan visi yang jelas dan menantang; (2) menjelaskan bagaimana visi tersebut dapat dicapai; (3) bertindak percaya diri dan optimis; (4) mengekspresikan kepercayaan diri kepada para pengikutnya; (5) menggunakan tindakan-tindakan dramatis dan simbolis untuk menekankan nilai-nilai inti; (6) memimpin melalui contoh-contoh(Laurie J. Mullins, 2010).

Dikemukakan oleh Castanheira dan Costa, Kepemimpinan transformasional memiliki tiga fungsi dasar.Pertama, pemimpin transformasional secara tulus melayani kebutuhan orang lain, memberdayakan mereka dan menginspirasi pengikut untuk mencapai keberhasilan yang besar.Kedua, pemimpin transformasional memimpin dengan karisma, menetapkan visi, menanamkan trust, kepercayaan diri (confidence), dan kebanggaan dalam bekerja bersama pengikutnyamelalui stimulasi intelektual pemimpin transformasional menanamkan kepemimpinan terhadap pengikutnya.

Karakteristik-karakteristik kepemimpinan transformasional sebagaimana dikemukakan di atas sangatlah penting pada masa perubahan keorganisasian. Dalam konteks ini pemimpin transformasional menurut Shadraconis membimbing organisasi yang mengalami peristiwa krisis melalui proses pembentukan makna (sensemaking) dengan memberikan struktur dalam bentuk visi yang bersifat menantang. Selanjutnya menurut Hunt, Boal, dan Dodge sebagaimana dikutip oleh Shadraconis (2013), dalam situasi krisis kepemimpinan semakin dibutuhkan dan pemimpin memiliki peran yang sangat penting dalam proses pemberian makna pada masa krisis. Melalui penciptaan suasana pemberdayaan dan membimbing pengikut dalam proses pembentukan makna selama masa krisis, 
pemimpin transformasional mampu membendung terjadinya disintegrasi kelompok sebagai penyebab kegagalan organisasi. Berdasarkan pemahaman ini dapat disimpulkan bahwa pemimpin transformasional merupakan sosok pemimpin yang memberdayakan para pengikutnya.

Menurut McShane dan Von Glinow terdapat empat unsur kepemimpinan transformasional, yaitu; (1) menciptakan visi yang strategik (create a strategic vision); (2) mengkomunikasikan visi (communicate vision); (3) mencontohkan visi (model the vision); dan (4) membangun komitmen terhadap visi (buid commitment to the vision). Sedangkan Jennifer M George dan Gareth R. Jones menegaskan bahwa karakteristik kepemimpinan transformasional meliputi: (1) Meningkatkan kesadaran para pengikutnya akan pentingnya tugas dan pentingnya melaksanakan tugas dengan baik; (2) Menyadarkan para bawahannya akan perlunya pertumbuhan, perkembangan, dan pencapaian individu, dan (3) Memotivasi para bawahannya untuk bekerja demikebaikan organisasi daripada semata-mata memikirkan keuntunganpribadi.

Dirumuskan oleh Luthans (2010) ciri seorang yang telah berhasil menerapkan gaya kepemimpinan transformasional adalah: (a) mengidentifikasikan dirinya sebagai agen pembaharuan, (b). Memiliki sifat pemberani, (c) mempercayai orang lain, (d) bertindak atas dasar sistem nilai (bukan atas dasar kepentingan individu, atas dasar kepentingan dan desakan kroninya), (e) meningkatkan kemampuannya secara terus menerus, (f) memiliki kemampuan untuk menghadapi situasi yang rumit, tidak jelas dan tidak menentu, dan (g) memiliki visi ke depan.

Berdasarkan penjelasan para ahli sebagaimana diuraikan di atas dapat disimpulkan bahwa pada dasarnya terdapat empat dimensi utama kepemimpinan transformasional, yaitu; (1) pengaruh ideal (idealized influence); (2) motivasi inspirasi (motivational inspiration); (3) stimulasi intelektual (intelectual stimulation); (4) individualized consideration (pertimbangan individu).

Berbagai hasil penelitian menunjukkan efektifitas gaya kepemimpinan transformasional dalam organisasi. Hasil penelitian Rose Su-Jung Lin dan JuiKuo Hsiao dengan judul 'The relationship between transformational leadership, knowledge sharing, trust and organizational citizenship behaviour" menunjukkan bahwa kepemimpinan transformasional berhubungan secara signifikan dengan knowledge sharing dan trust.Hubungan antara kepemimpinan transformasional dan niat karyawan untuk berbagi pengetahuan menunjukkan korelasi positif yang signifikan.

Hasil penelitian di atas menunjukkan bahwa pemimpin yang berjiwa transformasional mampu membangkitkan niat atau keinginan bawahan untuk saling berbagi pengetahuan dengan pemimpinnya serta menumbuhkan trust.Sebagaimana dikemukakan sebelumnya trust in leadership pada masa perubahan memiliki peran sentral bagi keberhasilan perubahan. Semakin tinggi trust bawahan pada pimpinan, semakin rendah kecenderungan terjadi resistensi. 
Sebaliknya bawahan yang menaruh kepercayaan yang rendah pada pimpinan berpotensi memunculkan sikap resisten terhadap perubahan.

Dalam konteks organisasi sekolah, berbagai penelitian yang dilakukan menyoroti fungsi-fungsi penting yang diperankan pemimpin transformasional sekolah dalam memperbaiki pendidikan.Berdasarkan keterangan di atas, peneliti meneliti pengaruh langsung positif kepemimpinan transformasional terhadap keinovatifan

\section{METODE PENELITIAN}

Metode yang digunakan dalam penelitian ini adalah metode survei dengan pendekatan penelitian kuantitatif dengan teknik korelasi, dan sample pada penelitian ini adalah 38 guru dari 9 SMA dilubuklinggau. Teknik pengumpulan data dilakukan dengan menggunakan instrumen penelitian berbentuk kuesioner yang disusun sendiri oleh peneliti dibawah bimbingan tim promotor. Pernyataanpernyataan di dalam kuesioner survei berjenis pertanyaan tertutup dengan menggunakan skala Likert tentang kepemimpinan transformational.

\section{HASIL DAN PEMBAHASAN}

\section{Variabel Kepemimpinan Transformasional Kepala Sekolah}

Dari data yang diperoleh di lapangan yang kemudian diolah secara statistik ke dalam daftar distribusi frekuensi, banyaknya kelas di hitung menurut aturan Sturges, diperoleh tujuh kelas dengan nilai skor maksimum 199 dan skor minimum 130, sehingga rentang skor sebesar 69.

Berdasarkan hasil perhitungan statistik deskriptif diperoleh bahwa instrumen Kepemimpinan Transformasional Kepala Sekolah mempunyai nilai rata-rata (mean) adalah 165,19, nilai yang sering muncul (modus) 141, nilai tengah (median) 167, standar deviasi adalah 19,83, dan varians 388,03, untuk melihat sebaran data variabel Kepemimpinan Transformasional Kepala Sekolah tersebut disajikan pada tabel distribusi frekuensi sebagai berikut:

Tabel.1

Distrlibusi Frekuensi Kepemimpinan Transformasional Kepala Sekolah

\begin{tabular}{cccccc}
\hline Kelas & Interval Data & Frek. Relatif & Frek. Kumulatif & \% Relatif & \% Kumulatif \\
\hline I & $130-139$ & 8 & 8 & $10.26 \%$ & $10.26 \%$ \\
II & $140-149$ & 10 & 18 & $12.82 \%$ & $23.08 \%$ \\
III & $150-159$ & 12 & 30 & $15.38 \%$ & $38.46 \%$ \\
IV & $160-169$ & 15 & 45 & $19.23 \%$ & $57.69 \%$ \\
V & $170-179$ & 13 & 58 & $16.67 \%$ & $74.36 \%$ \\
VI & $180-189$ & 11 & 69 & $14.10 \%$ & $88.46 \%$ \\
VII & $190-199$ & 9 & 78 & $11.54 \%$ & $100.00 \%$ \\
\hline \multicolumn{7}{c}{ Jumlah } & 78 & & $100 \%$ & \\
\hline
\end{tabular}


Berdasarkan tabel 1 di atas, selanjutnya dibuat histogramnya. Ada dua sumbu yang diperlukan dalam pembuatan histogram yakni sumbu vertikal sebagai sumbu frekuensi absolut, dan sumbu horizontal sebagai sumbu skor perolehan instrumen. Dalam hal ini pada sumbu horizontal tertulis batas-batas kelas interval yaitu mulai dari 129,5 sampai 199,5. Harga-harga tersebut diperoleh dengan jalan mengurangkan angka 0,5 dari data terkecil dan menambahkan angka 0,5 setiap batas kelas pada batas tertinggi. Nilai hasil Kepemimpinan Transformasional Kepala Sekolah yang diperoleh dari 78 orang responden dapat divisualisasikan dalam bentuk grafik histogram menjadi sebagai berikut:

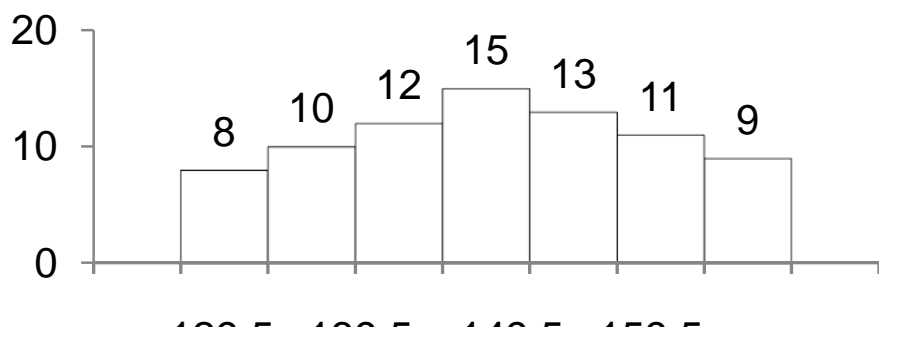

Hasil pengujian hipotesis menunjukkan bahwa kepemimpinan transformasional berpengaruh langsung positif terhadap keinovatifan. Berdasarkan data hasil penelitian ini, penerapan kepemimpinan transformasional oleh kepala sekolah dengan mengembangkan visi bersama dan membangun kesepakatan tujuan, memberikan dukungan terhadap para guru, memberi contoh perilaku, memberikan penghargaan terhadap kinerja guru yang tinggi, membangun struktur kerjasama, serta memperkuat budaya sekolah mampu mendorong keinovatifan guru yang dibuktikan dengan semakin tingginya tingkat penerimaan guru terhadap gagasan-gagasan baru baik terkait dengan metode-metode maupun media-media pembelajaran yang kemudian diterapkan dalam pembelajaran di kelas. Hasil penelitiain ini sesuai dengan pendapat Moolenaar yang menyatakan, "transformational leadership is positively associated with school's innovative climate and it motivates followers to do more than they are expected in terms of extra effort and greater productivity.

Artinya adalah bahwa kepemimpinan transformasional secara positifberhubungan dengan iklim inovatif sekolah dan memotivasi pengikutnya untuk berbuat melibihi apa yang diharapkan. Sedangkan McShane dan Von Glinow menyatakan, "transformasional leadership is about "leading" - changing the organization's strategies and culture so that they have a better fit with surrounding environment. Tranformational leaders are change change agents who energize and direct employees to a new set of corporate values and behaviours. Kepemimpinan transformasional berkaitan dengan memimpin melakukan perubahan terhadap strategi dan budaya organisasi sehingga sesuai dengan lingkungan.Pemimpin transformasional adalah seorang agen perubahan 
yang menguatkan dan mengarahkan pengikutnya terhadap sejumlah nilai-nilai dan perilaku yang baru.Secara tersirat dapat disimpulkan bahwa kepala sekolah sebagai pemimpin transformasional adalah seorang agen perubahan yang menghendaki terjadinya perubahan-perubahan nilai dan perilaku para guru sehingga mampu memberikan layanan pendidikan yang bermutu sesuai dengan tuntutan lingkungan.Kepala sekolah yang berkarakter transformasional menghendaki para guru menjadi inovator yang effektif.

Berbagai hasil penelitian yang relevan antara lain dilakukan oleh Rabia Khan, Abaid Ur Rehma, dan Afsheen Fatima dengan judul "Transformational Leadership and Organizational Innovation". Hasil penelitian menunjukkan bahwa kepemimpinan transformational secara positif dan signifikan berhubungan dengan inovasi organisasi.Lebih jauh hasil penelitian mengindikasikan bahwa ukuran organisasi secara signifikan merupakan variabel moderator antara seluruh dimensi kepemimpinan transformasional (karisma, motivasi inspirasi, stimulasi intelektual, dan pertimbangan individu) dan inovasi organisasi.Selanjutnya hasil penelitian Lale Gumusluoglu dan Arzu Ilsev dengan judul "Transformational leadership, creativity, and organizational innovation". Hasil analisis regresi menunjukkan bahwa pada tingkat organisasi kepemimpinan transformasional secara positif berhubungan dengan inovasi organisasi.

Demikian halnya dengan penelitian yang dilakukan oleh Siroos Ghanbari dan Asghar Eskandari yang berjudul, "Transformational Leadership, Job satisfaction, and Organizational Innovation". Hasil penelitian menunjukkan bahwa terdapat hubungan yang positif antara kepemimpinan transformasional dengan inovasi organisasi. Dalam hal ini pemimpin transformasional membantu guru menjadi kreatif, inovatif dan membawa ide-ide baru, pemikiran, dan metodemetode mengajar yang membuat sekolah tumbuh lebih baik dan mampu menyesuaikan diri dengan lingkungan eksternal yang selalu berubah. Faktorfaktor pertimbangan individu dan pengaruh ideal memberikan dampak terbesar sebagai prediktor inovasi organisasi. Dengan demikian temuan penelitian ini mendukung pendapat yang menyatakan bahwa kepemimpinan transformasional berpengaruh terhadap keinovatifan.

\section{SIMPULAN}

Terdapat pengaruh langsung positif kepemimpinan transformasional terhadap keinovatifan. Artinya, jika kepemimpinan transformasional kepala sekolah efektif, keinovatifan guru tinggi. Kepemimpinan transformasional berpengaruh langsung positif terhadap keinovatifan, sehingga untuk meningkatkan keinovatifan guru perlu ditingkatkan efektifitas kepemimpinan transformasional kepala sekolah. Upaya peningkatan keinovatifan ini dapat dilaksanakan dengan cara kepala sekolah membangun iklim yang mendukung inovasi. Selanjutnya kepala sekolah mengembangkan kemampuan-kemampuan 
inovatif guru dan mendorong guru untuk mencoba ide-ide atau pendekatanpendekatan baru dalam menyelesaikan permasalahan-permasalahan pembelajaran.

\section{DAFTAR PUSTAKA}

Bass, B.M. (1985). Leadership and Performance Beyond Expectations. New York: TheFree Press

Burns, J.M. (1978). Leadership. New York, NY: Harper \& Row

Colquit, L., \& Wesson, W. 2011). Organizational Behaviour, Second Edition (New York: McGraw-Hill/Irwin, 2011), h.496

Luthans, F. (2011). Organizational Behaviour, Twelfth Edition. New York:-Hill, 2011

Hallinger, H. (2013). Transformational Approach to Scholl Leadership: Contribution to Continued Improvement of Education. Journal of Change and Leadership, (17), 239

James, L. G. (2012). Organizations: Behaviour, Structure, Processes (New York: McGraw-Hill, 2012), h. 356

Jennifer, M. G., \& Gareth, R. J. (2012). Understanding and Managing Organizational Behavior, Sixth Edition (USA : Pearson Education, Inc, 2012), h. 356

Laurie J. M. (2010). Management and Organizational Behavior, Ninth Edition (Great Britain: Pearson Education Limited, 2010), hh.391-392

Mcshane, M., \& Glinow, V. (2010). Organizational Behaviour, Fifth Edition (New York: McGraw- Hill/Irwin, 2010), h. 371

Robert, K., \& Angelo, K. (2010). Organizational Behavior, Ninth Edition, (New York: McGraw-Hill Irwin, 2010), h.485

Shadraconis, S. (2013). Organizational Leadership in Time of Uncertainty: Is Transformasional Leadership the Answer? LUX: A Journal of Transdisciplinary Writing and Research from Claremont Graduate University, 2(1), 1-15

Stephen, P. R., \& Timothy, A. J. (2013). Organizational Behaviour, Fifteenth Edition (USA: Pearson Education, Inc), h.383

Tichy, T., \& Ulrich, U. (2013). Transformational Leadership, Background Literature Review, IGBC, h.5 